\title{
Enterobacterales Üyelerinde Nadir Bir Plazmid Aracılı A Sınıfı Beta Laktamaz Olan IBC-1'in Araştırılması
}

\author{
Investigation of IBC-1, a Rare Plasmid-Mediated Class A Beta-lactamase in \\ Members of Enterobacterales
}

\author{
Gülşen Altınkanat Gelmez ${ }^{1}$, Ufuk Hasdemir ${ }^{1}$ [D, Güner Söyletir ${ }^{1}$ (i) \\ 'Marmara Üniversitesi, Tıp Fakültesi, Tıbbi Mikrobiyoloji Anabilim Dalı, İstanbul, Türkiye
}

ORCID ID: G.A.G. 0000-0003-0274-628X; U.H. 0000-0002-1606-0804; G.S. 0000-0001-5695-731X

Cite this article as: Altınkanat Gelmez G, Hasdemir U, Söyletir G. Enterobacterales üyelerinde nadir bir plazmid aracılı a sınıfı beta laktamaz olan IBC-1'in araştırılması. Experimed 2021; 11(2): 81-7.

\section{öz}

Amaç: Bu çalışmanın amacı, tüm dünyada sıklıkla gözlemlenen geniş spektrumlu beta laktamazları (GSBL) TEM, SHV ve CTX-M ve nadir görülen IBC-1 beta laktamaz enziminin varlığını araştırmaktır.

Gereç ve Yöntem: Marmara Üniversitesi Hastanesinde yatan hastaların klinik örneklerinden izole edilen, fenotipik olarak GSBL üreten ve IBC-1 fenotipi gösteren 30 köken çalışmaya dahil edilmiştir. Antibiyotik duyarlılık testleri disk difüzyon ve agarda dilüsyon yöntemi ile gerçekleştirilmiştir. GSBL enzimlerinin fenotipik olarak saptanmasında E-test ve çift disk sinerji yöntemi kullanılmıştır. GSBL üretiminden sorumlu olan genlerinin varlığını saptamak amacıyla polimeraz zincir reaksiyonu (PZR) yapılmıştır.

Bulgular: Kökenlerin tamamı, imipeneme duyarlı bulunurken, ampisilin, amoksisilin klavulanik asit, piperasilin, seftazidim ve trimetoprim sülfametaksazole dirençli olarak; saptanmıştır. E-test yöntemiyle 4 köken tanımsız, 26 köken ise GSBL pozitif saptanmıştır. Çift disk sinerji yöntemi ile 2 köken fenotipik olarak IBC-1 pozitif iken, 5 köken şüpheli pozitif olarak belirlenmiştir. Kökenlerimizin bla $_{T E M}$, bla $_{S H V}$ ve bla CTX-M $_{\text {g }}$ genlerini taşıma oranı sırasıyla $\% 73,3, \% 60$ ve $\% 56,6$ olarak belirlenmiştir. bla $a_{I B C}$ geni ise hiçbir kökende saptanmamıştır.

Sonuç: Illk olarak Yunanistan'da saptanan IBC-1 enzimi ülkemiz için henüz bir tehlike oluşturmazken GSBL pozitif kökenlerde TEM, SHV ve CTX-M enzimlerinin oranı oldukça yüksek olarak tespit edilmiştir.

Anahtar Kelimeler: GSBL, IBC-1, E. coli, K. pneumoniae, E. cloacae

\section{ABSTRACT}

Objective: The aim of the study was to investigate the presence of extended -spectrum beta-lactamases (ESBL) TEM, SHV, and CTX-M which are frequently observed all over the world, and the rare IBC1 beta-lactamase enzyme.

Material and Method: Thirty strains that isolated from various clinical samples from inpatient at Marmara University Hospital, which were phenotypically positive for ESBL, and IBC-1 were included in the study. Antimicrobial susceptibility tests were performed both by disk diffusion and agar dilution tests. E-test and double-disc synergy method (DDS) were used for phenotypic detection of ESBLs. The presence of ESBL genes was detected by polymerase chain reaction (PCR).

Results: All strains were susceptible to imipenem while ampicillin, amoxicillin-clavulanic acid, piperacillin, ceftazidime, and trimethoprim-sulfamethoxazole were resistant. While 4 strains were unidentified, 26 strains were detected as ESBL positive by E-test. Two strains were phenotypically positive for IBC-1 with DDS, while 5 strains were identified as doubtful. The rate of carrying the bla $\mathrm{T}_{T E M}$, bla $_{S H V}$, and bla $_{C T X-M}$ genes of strains was $73.3 \%, 60 \%$, and $56.6 \%$, respectively. The bla $\mathrm{a}_{B C}$ gene was not detected in any of the strains.

Conclusion: While the IBC-1 enzyme, which was first detected in Greece, have not caused a threat to our country yet, the rate of TEM, SHV, and CTX-M enzymes were found to be quite high.

Keywords: $\mathrm{ESBL}, \mathrm{IBC}-1$, E. coli, K. pneumoniae, E. cloacae 


\section{GíRiş}

Beta-laktam antibiyotiklere karşı en önemli direnç mekanizması bir beta laktamaz enzimi üretimidir. Yeni beta-laktam antibiyotiklerin kullanıma girmesi ile birlikte ilerleyen yıllarda "genişlemiş spektrumlu beta-laktamazlar (GSBL)" ortaya çıkmıştır. Çoğunlukla plazmidler aracılığıyla aktarılan GSBL'ler 3. kuşak sefalosporinleri ve monobaktamları hidrolize ederek direnç gelişimine neden olurlar. GSBL üretimi Escherichia coli ve Klebsiella pneumoniae kökenleri başta olmak üzere Enterobacteriaceae ailesinde bulunan en yaygın direnç mekanizmasıdır. GSBL tipleri ve sıklıkları çeşitli ülkelere, coğrafik bölgelere, hatta hastanelere göre değişmektedir. GSBL üreten kökenlerin artan oranlarda izole edilmesi, bu kökenlerle gelişen enfeksiyonların tedavisini güçleştirmekte ve morbidite ve mortalite oranlarında artışa neden olmaktadır. Plazmidler tarafından kodlanan ana enzim aileleri TEM, SHV, CTX-M ve OXA tipi enzimlerdir. Ana enzimleri kodlayan genlerde meydana gelen mutasyonlar sonucu yeni varyant enzimler ortaya çıkmıştır. Bununla birlikte çeşitli bölgelerde sporadik olarak TEM ve SHV dışı GSBL'ler (VEB, GES, IBC, PER, TLA, BES ve SFO) gözlemlenmektedir (1-3).

IBC-1, nadir görülen bir geniş spektrumlu beta laktamaz olup, 1998-2000 yılları arasında Selanik Hippokration Hastanesinde izole edilen bir Enterobacter cloacae kökeninde tanımlanmıştır (4). Atina'da yapılan bir çalışmada $b / a_{\mathrm{IBC}-1}$ geninin, yeni bir sınıf 1 integron olan In111'de kodlandığı bulunmuştur. IBC-1'in nükleotid dizilimi incelendiğinde yapısal olarak sınıf $A$ beta laktamazlara benzediği ve diğer beta laktamazlardan birkaç aminoasit residüsü ile ayrıldığı saptanmıştır. IBC-1 fenotipi, seftazidime yüksek düzey dirençli, sefotaksim, sefepim ve aztreonama azalan duyarlılıkta, klavulanik asit ve piperasilin tazobaktama diğer GSBL'lere göre daha az duyarlı ve imipenem ile inhibe olduğu saptanmıştır $(5,6)$. Yunanistan'da ilerleyen yıllarda yapılan farklı çalışmalarda Klebsiella pneumoniae, Escherichia coli ve Pseudomonas aeruginosa kökenlerinde IBC-1 beta laktamaz enzimi saptanmıştır (6-8).

Hastanemizde çoklu antibiyotik direnci gösteren Escherichia coli, Klebsiella pneumoniae ve Enterobacter cloacae kökenlerinin azımsanmayacak oranda izole edilmesinden dolayı bu kökenlerdeki antibiyotik direnç mekanizmalarının belirlenmesi, hastanemizin antibakteriyel tedavi stratejilerinin oluşturulmasında önemlidir. Bu nedenle çalışmamızda, hastanemizde enfeksiyon etkeni olarak izole edilen gram negatif bakterilerde çoklu antibiyotik direncinden sorumlu tutulan IBC-1'in yanı sıra TEM, SHV ve CTX-M türü GSBL enzimlerinin yaygınlığının araştırılması amaçlanmıştır.

\section{GEREÇ VE YÖNTEM}

\section{Bakterilerin Seçimi}

Ocak 2004-Aralık 2005 yılları arasında Marmara Üniversitesi Hastanesinde yatan hastaların klinik örneklerinden etken olarak izole edilen, fenotipik olarak GSBL pozitif veya tanımsız olduğu belirlenen ve IBC-1 fenotipine (beta laktam ve beta laktam-klavulanat kombinasyonlarına dirençli, seftazidime di- rençli, imipeneme duyarlı) uygun Klebsiella pneumoniae $(n=12)$, Escherichia coli $(n=11)$, ve Enterobacter cloacae $(n=7)$ kökenleri bu çalışmaya dahil edilmiştir.

\section{Antibiyotik Duyarlılık Testleri}

Kökenlerin, beta laktam grubu antibiyotiklere duyarlılıkları (ampisilin, amoksisilin klavulanik asit, piperasilin, piperasilin tazobaktam, sefoksitin, seftazidim, sefotaksim, sefepim ve imipenem) agar dilüsyon yöntemi ile saptanırken, beta laktam dışı antibiyotiklere (gentamisin, tobramisin, netilmisin, amikasin, tetrasiklin ve trimetoprim sülfametaksazol) duyarlılıkları ise disk difüzyon yöntemi ile belirlenmiştir. Sonuçlar; Klinik ve Laboratuvar Standartları Enstitüsü (Clinical and Laboratory Standards Institute; CLSI) kriterlerine göre değerlendirilmiştir (9). Çalışma süresince Escherichia coli ATCC 25922 standart köken olarak kullanılmıştır.

IBC-1 ve GSBL Üretiminin Fenotipik Yöntemlerle Saptanması Gradient-test: Kökenlerin GSBL üretimi E-test (AB Biodisk, Solna, Sweden) stripleri ile saptanmıştır. 18-24 saatlik kültürden 0,5 McFarland bulanıklığında bakteri süspansiyonu hazırlanarak Mueller-Hinton Agar (MHA) besiyerinin üzerine steril eküvyon yardımıyla yayılmıştır. Seftazidim/seftazidim klavulanik asit (TZ/TZL) ve sefotaksim/sefotaksim klavulanik asit (CT/CTL) E-test stripleri MHA besiyeri üzerine yerleştirilmiştir. $35^{\circ} \mathrm{C}$ 'de 16-18 saat inkübasyondan sonra TZ minimum inhibisyon konsantrasyonu (MiK) değerinin TZL MiK değerine oranı $\geq 8$ ya da CT MiK değerinin CTL MiK değerine oranı $\geq 8$ ise GSBL üretimi açısından pozitif olarak değerlendirilmiştir.

Çift disk sinerji yöntemi: Kökenlerin GSBL üretimi çift disk sinerji yöntemiyle saptanmıştır. 18-24 saatlik kültürlerden 0,5 McFarland bulanıklığında bakteri süspansiyonu hazırlanarak MHA besiyerinin üzerine steril eküvyon yardımıyla yayıımıştır. Diskler arası uzaklık 15-17 mm olacak şekilde merkeze seftazi$\operatorname{dim}(30 \mu \mathrm{g})$, çevresine amoksisilin klavulanik asit $(20 / 10 \mu \mathrm{g}), \mathrm{pi}-$ perasilin tazobaktam $(100 / 10 \mu \mathrm{g})$ ve imipenem $(10 \mu \mathrm{g})$ diskleri yerleştirilmiştir. $35^{\circ} \mathrm{C}^{\prime}$ de $16-18$ saat inkübasyondan sonra, seftazidim diskinin inhibisyon zonunun amoksisilin klavulanik asit ve piperasilin tazobaktam disklerine doğru genişlemesi GSBL varlığı olarak kabul edilmiştir. Seftazidim diskinin imipenem diskine doğru genişlemesi, IBC-1 enzimi varlığı açısından pozitif olarak kabul edilmiştir (Resim 1/A).

IBC-1 ve GSBL Varlığının Genotipik Yöntemlerle Saptanması Beta laktamaz genlerinin varlığının saptanabilmesi için bakteri DNA'ları üretici firmanın önerileri doğrultusunda QIAGEN DNA izolasyon kiti ile izole edilmiştir. Kökenlerde $b l a_{\mathrm{IBC}}, b l a_{\mathrm{TEM}}, b l a_{\mathrm{S}-}$ $\mathrm{HV}$ ve $b a_{\mathrm{CTX}-\mathrm{M}}$ genlerinin varlığını tespit etmek için polimeraz zincir reaksiyonu (PZR) kullanılmıştır $(6,10)$. PZR için kullanılan primerler ve reaksiyon şartları Tablo 1'de belirtilmiştir. Elde edilen PZR ürünleri, etidyum bromür varlığında \%2'lik agaroz jelde yürütülüp ultraviyole ışık altında değerlendirilmiş̧tir.

\section{BULGULAR}

Çalışmamızda kullandığımız kökenlerin tamamı, her iki yöntem ile imipeneme duyarlı iken, ampisilin, piperasilin ve seftazidime 

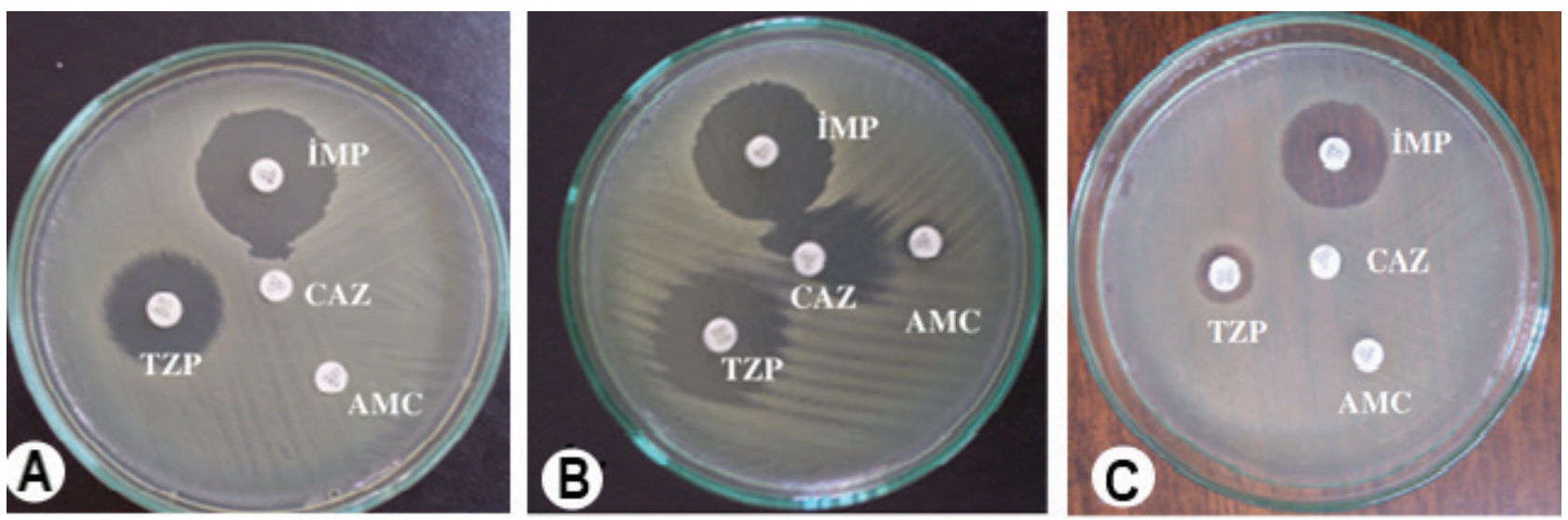

Resim 1. bla $a_{\mathrm{IBC}-1}$ geni pozitif olduğu bilinen Enterobacter cloacae HT9 kökeninin çift disk sinerji yöntemiyle görünüşü (A). Çift disk sinerji yöntemiyle IBC pozitif değerlendirilen köken (B). Çift disk sinerji yöntemiyle IBC negatif değerlendirilen köken (C).

Tablo 1. Geniş spektrumlu beta laktamaz genlerine özgü primer ve reaksiyon koşulları.

\begin{tabular}{|c|c|c|c|}
\hline Gen & Primer Dizisi(5'-3') & bp & Reaksiyon Koşulları \\
\hline IBC-F & 5'- CCC CAA GGA GAG ATC GTC G-3' & \multirow[b]{2}{*}{861} & \multirow[b]{2}{*}{$95^{\circ} \mathrm{C} 5 \mathrm{dk}, 30$ siklus $\left(95^{\circ} \mathrm{C} 1 \mathrm{dk}, 60^{\circ} \mathrm{C} 1 \mathrm{dk}, 72^{\circ} \mathrm{C} 1 \mathrm{dk}\right), 72^{\circ} \mathrm{C} 10 \mathrm{dk}$} \\
\hline $\mathrm{IBC}-\mathrm{R}$ & 5'-GTA ATC TCT CTC CTG GGC TT-3' & & \\
\hline TEM-F & 5'-GAA GAC GAA AGG GCC TCG TG-3' & \multirow{2}{*}{1074} & \multirow{2}{*}{30 siklus $\left(94^{\circ} \mathrm{C} 30 \mathrm{sn}, 52^{\circ} \mathrm{C} 1 \mathrm{dk}, 72^{\circ} \mathrm{C} 90 \mathrm{sn}\right), 72^{\circ} \mathrm{C} 10 \mathrm{dk}$} \\
\hline TEM-R & 5'-GGT CTG ACA GTT ACC AAT GC-3' & & \\
\hline SHV-F & 5'-CGC CGG GTT ATT CTT ATT TGT CGC-3' & \multirow[b]{2}{*}{1016} & \multirow[b]{2}{*}{30 siklus $\left(94^{\circ} \mathrm{C} 45 \mathrm{sn}, 65^{\circ} \mathrm{C} 1 \mathrm{dk}, 72^{\circ} \mathrm{C} 3 \mathrm{dk}\right), 72^{\circ} \mathrm{C} 10 \mathrm{dk}$} \\
\hline SHV-R & 5'-TCT TTC CGA TGC CGC CGC CAG TCA-3' & & \\
\hline CTX-M-F & 5'-CGC TTT GCG ATG TGC AG-3' & \multirow[b]{2}{*}{544} & \multirow[b]{2}{*}{30 siklus $\left(94^{\circ} \mathrm{C} 1 \mathrm{dk}, 54^{\circ} \mathrm{C} 1 \mathrm{dk}, 72^{\circ} \mathrm{C} 2 \mathrm{dk}\right), 72^{\circ} \mathrm{C} 10 \mathrm{dk}$} \\
\hline CTX-M-R & 5'-ACC GCG ATA TCG TTG GT-3' & & \\
\hline
\end{tabular}

dirençli bulunmuştur. Kökenlerin tamamı disk difüzyon yöntemi ile amoksisilin klavulanik asite dirençli bulunurken agar dilüsyon yöntemiyle \%56,7'si dirençli, \%43,3'ü orta duyarlı bulunmuştur (Tablo 2).

Kökenlerin tamamı disk difüzyon yöntemi ile trimetoprim-sülfametaksazole dirençli bulunurken, tobramisin, tetrasiklin, netilmisin, gentamisin ve amikasine sırasıyla \%96,6, \%93,3, \%90, $\% 70$ ve \%20 dirençli olarak bulunmuştur (Tablo 2). Beta laktam antibiyotiklerin agar dilüsyon yöntemi ile belirlenen MiK $_{50}$ ve MiK $_{90}$ değerleri Tablo 2'de verilmiştir.

26 köken, hem TZ/TZL hem de CT/CTL E-test'leri ile GSBL pozitif bulunurken, 4 köken her iki E-test stripi ile tanımsız olarak değerlendirilmiştir. IBC enziminin varlığının fenotipik olarak saptanmasında kullanılan çift disk sinerji yöntemi ile 2 köken kesin pozitif olarak değerlendirilirken, 5 köken ise imipenem-seftazidim arasındaki zon genişlemesinin yanında amoksisilin-klavulanik asit-seftazidim ve piperasilin tazobaktam-seftazidim arasındaki zon genişlemelerinin varlığı sebebiyle şüpheli pozitif olarak değerlendirilmiştir (Resim 1).
Çalışmamızda kullanılan kökenlerin $5^{\prime} \mathrm{i}$ sadece bla ${ }_{\mathrm{SHV}}, 1^{\prime} \mathrm{i}$ bla $\mathrm{b}_{\mathrm{TEM}}$, ve 1'i de bla стх-м genleri tek başına taşırken, 22 kökenin iki veya daha fazla GSBL genini bir arada taşıdığı tespit edilmiştir. 1 kökenin ise bla $\mathrm{TEM}_{\mathrm{M}}$, bla $\mathrm{S}_{\mathrm{SHV}}$ ve bla ${ }_{\mathrm{CTX}-\mathrm{M}}$ genlerinden hiçbirini taşımadığı tespit edilmiştir. Buna göre TEM, SHV ve CTX-M enzimlerinin görülme oranları sırasıyla $\% 73,3, \% 60$ ve $\% 56,6$ olarak tespit edilmiştir. IBC-1 enziminin varlığı fenotipik yöntemlerle bazı kökenlerde pozitif olmasına rağmen, bütün kökenler PZR sonuçlarına göre, bla ${ }_{\mathrm{IBC}-1}$ geni açısından negatif bulunmuştur (Tablo 3).

\section{TARTIŞMA}

Hastaneler, mobil genetik elementler ile taşınan direnç genlerinin kişiden kişiye ve türler arasında yayılması için en ideal ortamlardır. Klinik önemi olan bakterilerde, özellikle hastane ortamında, bu mekanizmalar çoklu antibiyotik direncinin gelişimine yol açarak, hastanede yatış süresinin uzamasına, tedavide sorunların ortaya çıkmasına ve hatta enfeksiyonun ölümle sonuçlanmasına neden olmaktadır. Antibiyotik direnç mekanizmaları arasında GSBL üretimi, çoklu antibiyotik diren- 
Tablo 2. Kökenlerin antibiyotik duyarlılık sonuçları.

\begin{tabular}{|c|c|c|c|c|c|c|c|c|}
\hline \multirow[b]{2}{*}{ Antibiyotik } & \multicolumn{3}{|c|}{ Disk difüzyon Yöntemi (\%) } & \multicolumn{3}{|c|}{ Agar Dilüsyon Yöntemi (\%) } & \multirow{2}{*}{$\begin{array}{l}\text { MiK }_{50} \\
\text { (mg/L) }\end{array}$} & \multirow{2}{*}{$\begin{array}{l}\text { MiKK}_{90} \\
(\mathrm{mg} / \mathrm{L})\end{array}$} \\
\hline & $\mathbf{S}$ & $\mathbf{I}$ & $\mathbf{R}$ & $\mathbf{S}$ & $\mathbf{I}$ & $\mathbf{R}$ & & \\
\hline Ampisilin & 0 & 0 & 100 & 0 & 0 & 100 & $>256$ & $>256$ \\
\hline Amoksisilin Klavulanik Asit & 0 & 0 & 100 & 0 & 43,3 & 56,7 & 32 & 64 \\
\hline Piperasillin & 0 & 0 & 100 & 0 & 0 & 100 & $>256$ & $>256$ \\
\hline Piperasilin Tazobaktam & 50 & 26,6 & 23,4 & 43,4 & 33,3 & 23,3 & 32 & 128 \\
\hline Sefoksitin & 63,3 & 3,3 & 33,3 & 63,2 & 10 & 26,8 & 8 & $>256$ \\
\hline Seftazidim & 0 & 0 & 100 & 0 & 0 & 100 & 128 & $>256$ \\
\hline Sefotaksim & 0 & 23,3 & 76,6 & 0 & 13,2 & 86,8 & 128 & $>256$ \\
\hline Sefepim & 266 & 20 & 52 & 30,1 & 16,6 & 53,3 & 16 & 32 \\
\hline İmipenem & 100 & 0 & 0 & 100 & 0 & 0 & 0,5 & 0,5 \\
\hline Aztreonam* & 0 & 3,3 & 96,6 & - & - & - & - & - \\
\hline Gentamisin* & 26,6 & 3,3 & 70 & - & - & - & - & - \\
\hline Tobramisin* & 52 & 0 & 96,6 & - & - & - & - & - \\
\hline Netilmisin* & 6,6 & 3,3 & 90 & - & - & - & - & - \\
\hline Amikasin* & 52 & 26 & 20 & - & - & - & - & - \\
\hline Tetrasiklin* & 6,6 & 0 & 93,3 & - & - & - & - & - \\
\hline Trimetoprim Sülfametaksazol* & 0 & 0 & 100 & - & - & - & - & - \\
\hline $\begin{array}{l}\text { *Sadece disk difüzyon yöntemi ile çalışıın } \\
\text { S: Duyarlı, I: Orta Duyarlı, R: Dirençli, MiK: }\end{array}$ & um inhik & nsantra & & & & & & \\
\hline
\end{tabular}

Tablo 3. Geniş spektrumlu beta laktamaz genlerinin dağılımı.

\begin{tabular}{lcccc}
\hline GSBL Geni & $\begin{array}{c}\text { Klebsiella pneumoniae } \\
(\mathbf{n}=\mathbf{1 2})\end{array}$ & $\begin{array}{c}\text { Escherichia coli } \\
(\mathbf{n = 1 1 )}\end{array}$ & $\begin{array}{c}\text { Enterobacter cloacae } \\
(\mathbf{n}=\mathbf{7})\end{array}$ & $\begin{array}{c}\text { Toplam } \\
(\mathbf{n}=\mathbf{3 0})\end{array}$ \\
\hline TEM & 1 & 0 & 3 & 1 \\
\hline SHV & 1 & 1 & 0 & 5 \\
\hline CTX-M & 0 & 1 & 3 & 1 \\
\hline TEM+SHV & 3 & 0 & 0 & 6 \\
\hline TEM+CTX-M & 2 & 7 & 1 & 9 \\
\hline SHV+CTX-M & 1 & 0 & 0 & 2 \\
\hline TEM+SHV+CTX-M & 4 & 1 & 0 & 5 \\
\hline IBC-1 & 0 & 0 & 0 & 0 \\
\hline Negatif & 0 & 1 & 1 \\
\hline
\end{tabular}

cine sebep olan önemli bir mekanizma olup, özellikle hastane enfeksiyonu etkeni gram negatif bakterilerde (Klebsiella, E. coli, Enterobacter spp. vb.) yaygın olarak bulunmaktadır. Yeni geliştirilen antibiyotiklerin uzun süreli etkin olarak klinik kullanımda kalması bunlara karşı yeni GSBL'lerin ortaya çıkmasına neden olmaktadır. Bu durum günümüzde enfeksiyon hastalıklarının tedavisinde hem insan hayatını tehdit eden hem de maliyet açısından büyük yükümlülükler getiren bir tablonun ortaya çıkmasına neden olmaktadır. Yeni GSBL'lerin tiplendirilmesi, bunların ortaya çıkış mekanizmalarının belirlenmesi, enfeksiyon 
etkeni bakteriler arasındaki yaygınlıklarının ortaya konması, gelecekteki antibakteriyel tedavi stratejilerinin saptanmasında önemli rol oynayacaktır $(11,12)$.

TEM, SHV ve CTX-M dışı GSBL'ler (VEB, GES, IBC, PER, TLA, BES ve SFO) ise nadir gözlemlenen aynı zamanda çeşitli coğrafik bölgelere özgü oldukları belirlenen enzimlerdir. Buna rağmen bu enzimlerin aktarılabilir plazmidlerde kodlanması, bölgeler arasında bu enzimlerin yayılabileceğini ve risk oluşturabileceğini düşündürmektedir. Bu nedenle risk altında bulunan bölgelerde belirli aralıklarla bu enzimlerin varlığının araştırılması ve tiplendirilmesi hem bu enzimler yoluyla oluşan direncin daha iyi anlaşılması hem de bunlara karşı önlem alınması açısından önemlidir (13).

İlk olarak Yunanistan'da tespit edilen IBC-1 enzimi bir Enterobacter cloacae (HT9) kökeninde tespit edilmiş ve seftazidime, klavulanat kombinasyonlarına dirençli olduğu, piperasilin tazobaktam ve klavulanik aside göre imipenem ile daha iyi inhibe olduğunu saptanmıştır. Aynı zamanda bu kökenin gentamisin hariç aminoglikozidlere ve trimetoprim sülfametaksazole çapraz direnç gösterdiği belirlenmiştir (4). Çalışmamızda kullandığımız kökenler de seftazidime, beta laktam/ beta laktamaz inhibitörlerine dirençli, imipeneme duyarlı olması nedeniyle IBC-1 fenotipine uymaktadır. Aynı zamanda kökenlerin, \%90'dan fazlasının netilmisin ve tobramisine dirençli bulunması, gentamisin direncinin ise görece olarak daha düşük olması literatürdeki IBC-1 fenotipi ile de benzerlik göstermektedir. Tüm Enterobacter cloacae kökenlerimiz IBC-1 fenotipi ile tamamen uyum göstermekte olup sefoksitin ve aztreonama da dirençli bulunmuştur.

Kartali ve ark. yoğun bakım ünitesinden izole edilen 27 Enterobacter cloacae kökeninin 18'inin IBC-1 enzimi ürettiğini saptamışlar ve bu kökenlerin rutin laboratuvarda tespitinde seftazidim-imipenem sinerji testinin yarar sağladığından bahsetmişlerdir (14). Vourli ve ark. 271 Klebsiella pneumoniae kökeninin 32'sinde PZR ile bla $a_{\mathrm{IBC}-1}$ varlığın göstermişler ancak seftazidim-imipenem sinerji testi bu kökenlerin 25 tanesini pozitif olarak değerlendirmişlerdir (6). Bizim çalışmamızda da kullandığımız imipenem-seftazidim sinerji testi ile fenotipik olarak 2 köken pozitif ve 5 köken ise şüpheli pozitif olarak değerlendirilmiştir. Ancak bu kökenlerin hiçbirinde PZR ile $b / a_{\mathrm{IBC}-1}$ genine rastlanmamıştır. Bu sonuçlar, IBC-1 enzimi açısından fenotipik yöntem olarak önerilen seftazidim-imipenem sinerji yönteminin henüz standardize olmadığını göstermektedir.

GES tipi enzimler ilk olarak 1998 yılında Fransa'da bir K. pneumoniae kökeninde saptanmıştır; penisilin ve sefalosporinlere dirençli, sefamisin ve karbapenemlere duyarlı olduğu bulunmuştur. 2001 yılında bir nokta mutasyonu ile farklılık gösteren IBC-1(GES-7) enzimi tanımlanmıştır. Sonradan IBC enziminin isimlendirilmesi GES olarak revize edilmiştir. Bugüne kadar 40'dan fazla GES varyantı saptanmıştır. Bu enzimlerden Gly170Asn veya Gly170Ser mutasyonlarına sahip 11 tanesi karbapenemaz aktivitesi göstermektedir. Diğer GES varyantları, herhangi bir karbapenem hidrolize edici aktivitesi olma- yan GSBL'ler olarak kategorize edilmiştir. GES tipi GSBL'lerde meydana gelen nokta mutasyonları ile karbapenemaz aktivitesi kazanmaları endişe verici bir durumdur. Nadir olmasına rağmen, GES karbapenemazları şu anda dünya çapında tanımlanmış olup, Yunanistan, Fransa, Portekiz, Güney Afrika, Brezilya, Arjantin, Kore, ABD, Kanada, Çin, Belçika ve Japonya'dan tek tek vakalar şeklinde bildirilmiştir. Türkiye'de yapılan çalışmalarda GES-11, GES-14 ve GES-22 üreten kökenler bildirilmiştir (15-17).

Çalışma sonuçlarımız GSBL pozitif mikroorganizmalarla enfekte olan hastaların tedavisinde beta laktam grubu antibiyotiklerin kullanılmasının başarısız sonuçlar doğuracağını ortaya koymaktadır. Buna ek olarak beta laktam/beta laktamaz inhibitörlü kombinasyonlara ve diğer antibiyotik gruplarına da çoklu direnç giderek artmaktadır. Nitekim GSBL pozitif ya da tanımsız olarak saptanan kökenlerimizin beta laktam dışı antibiyotiklere yüksek düzeyde direnç gösterdikleri (trimetoprim-sülfametaksazol direnci $\% 100$, tetrasiklin direnci $\% 93,3$, tobramisin direnci $\% 96,6$, netilmisin direnci \%90, gentamisin direnci \%70) gözlemlenmiştir.

Ülkemizden bildirilen birçok çalışmada olduğu gibi, hastanemizden izole edilen kökenlerimizde de TEM ve SHV enzimleri yaygın olduğu kadar CTX-M grubu enzimlerin oranı da oldukça fazladır (10,18-20). Çalışmamızda, PZR ile 12 Klebsiella pneumoniae kökenlerinin 10 'unda bla $a_{\mathrm{TEM}}$ geni, 9'unda bla $a_{\mathrm{SHV}}$, 7'sinde bla $a_{\text {CTX-M }}$ genleri pozitif olarak bulunmuştur. On bir Escherichia coli kökenlerinin 8'inde bla $a_{\mathrm{TEM}}$ geni, 2'sinde bla $a_{\mathrm{SHV}}$, 9'unda blaСTX-м genleri pozitif olarak bulunmuştur. Yedi Enterobacter cloacae kökenlerinin 4'ünde bla $a_{\mathrm{TEM}}, 7^{\prime}$ sinde $b l a_{\mathrm{SHV}}$, ${ }^{\prime}$ inde $b l a_{\mathrm{CTX}-\mathrm{M}}$ geni pozitif olarak bulunmuştur. 5 kökenimiz bla $a_{\mathrm{TEM}}, b l a_{\mathrm{SHV}}, b l a-$ CTX-M genlerini, 7 kökenimiz bla $a_{\mathrm{TEM}}$ ve bla $a_{\mathrm{SHV}}$ genlerini, 2 kökenimiz bla $a_{\mathrm{SHV}}$ ve bla $a_{\mathrm{CTX}-\mathrm{M}}$ genlerini, 8 kökenimiz bla $a_{\mathrm{TEM}}$ ve $b l a_{\mathrm{CTX}-\mathrm{M}}$ genlerini bir arada taşımaktadır. Bir Escherichia coli kökenimiz fenotipik yöntemlerle GSBL pozitif olmasına rağmen $b / a_{\mathrm{IBC}-1}$, bla $a_{\mathrm{TEM}}, b l a_{\mathrm{SHV}}$, bla $a_{\mathrm{CTX}-\mathrm{M}}$ genlerinden hiçbirini taşımadığı belirlenmiştir. Muhtemelen bu kökende başka bir enzim ya da başka bir direnç mekanizması mevcuttur. E-test ile tanımsız olarak değerlendirilen 4 kökenin PZR ile 2'sinde bla $a_{\mathrm{TEM}}$ ve $b / a_{\mathrm{SHV}}, 1$ 'inde $b l a_{\mathrm{SHV}}$ ve $b l a_{\mathrm{CTX}-\mathrm{M}}$ genleri bir arada bulunurken, 1 'inde sadece $b l a_{\text {SHV }}$ geni pozitif olarak bulunmuştur.

Marmara Üniversitesi hastanesinden, 2004 yılı itibariyle E. coli ve Klebsiella pneumoniae kökenlerinde GSBL pozitiflik oranı sırasıyla \%25 ve \%35 iken 2020 yılı itibariyle bu oran \%45,5 ve \%53,1dir. Çalışmamızın yapıldığı yıllarda yaygın görülen bu enzimler günümüzde de hala etkilerini sürdürmektedir. Bu enzimlerin yıllar içerisindeki hızlı artışının en önemli nedenleri, uygunsuz antibiyotik kullanımı, yetersiz raporlama, sağlıklı bireylerde gastrointestinal taşıyıcılığın artması, hastane enfeksiyonlarındaki belirgin artıştır. Aynı zamanda 2000'li yıllardan sonra GSBL pozitif kökenlerin toplum kökenli enfeksiyonlarda görülmeye başlanması oldukça önemlidir. 2000'li yılların öncesinde TEM ve SHV enzimleri sıklıkla saptanırken, günümüzde artık CTX-M tipi enzimler birinci sırada yer almaktadır. Yapılan çalışmalarda CTX-M geninin diğer antibiyotiklere direnç genle- 
ri ile beraber taşındığı saptanmıştır. Dolayısıyla yıllar içerisinde çoklu ilaç direncine sahip başarılı klonlar hızlı bir şeklide artış göstermiştir (21).

Antibiyotiklerin yaygın ve bilinçsiz kullanımı nedeniyle antibiyotik direnci önemli bir sorun haline gelmiştir. Her hastane, enfeksiyon etkeni olarak izole ettiği kökenlerinde antibiyotik direnç mekanizmalarını ve uygun antibiyotik kullanımını belirlemeli, beta laktamaz üretimini artıran beta laktam antibiyotiklerin kullanımını sınırlandırmalıdır. GSBL enzimleri dünyada olduğu gibi ülkemizde de yaygın olarak bulunmaktadır. Sonuçlarımız beta laktam antibiyotik direncinin ülkemizde önemli bir sorun olduğunu tekrar ortaya koymuştur. IBC-1 enzimi ise şimdiye kadar sadece Yunanistan'da saptanmış olup muhtemelen bölgesel sorun oluşturan bir GSBL'dir. Bizim çalışmamızda ve diğer ülkelerde yapılan çalışmalarda henüz bu enzime rastlanmamıştır. Bu bulgu her ne kadar şu andaki durumunu ifade ediyorsa da gelecekte bu enzimi üreten kökenlerin izole edilmeyeceğinin garantisini vermemektedir. Bu nedenle bu tür çaIışmaların belirli aralıklarla tekrar edilip ülkemize ait profillerin belirlenmesinde büyük yarar vardır.

Etik Komite Onayı: Bu çalışmada, etik komite iznine gerek duyulacak bir materyal ya da deney hayvanı kullanılmamıştır.

\section{Hakem Değerlendirmesi: Dış bağımsız.}

Yazar Katkıları: Çalışma Konsepti/Tasarımı - G.A.G., G.S., U.H.; Veri Toplama - G.A.G., G.S.; Veri Analizi/Yorumlama - G.A.G., G.S.; Yazma G.A.G.; İçeriğin Eleştirel İncelemesi - G.S., U.H.; Son Onay ve Sorumluluk - G.A.G., G.S., U.H.

Çıkar Çatışması: Yazarlar çıkar çatışması bildirmemişlerdir.

Finansal Destek: Bu çalışma Marmara Üniversitesi Bilimsel Araştırma Komisyonu tarafından desteklenmiştir (Proje no: SAG-YLS-100105-0005).

Ethics Committee Approval: Ethics committee approval is not required because of no material or experimental animal that would require permission.

Peer-review: Externally peer-reviewed.

Author Contributions: Conception/Design of Study - G.A.G., G.S., U.H.; Data Collection - G.A.G., G.S.; Analysis and/or Interpretation - G.A.G., G.S.; Drafting Manuscript - G.A.G.; Critical Revision of Manuscript - G.S., U.H.; Final Approval and Accountability - G.A.G., G.S., U.H.

Conflict of Interest: The authors have no conflict of interest to declare.

Financial Disclosure: This study was supported by Marmara University Scientific Research Projects Commission (Project no: SAG-YLS-100105-0005).

\section{KAYNAKLAR/REFERENCES}

1. Paterson DL, Bonomo RA. Extended-spectrum beta-lactamases: a clinical update. Clin Microbiol Rev 2005; 18(4): 657-86. [CrossRef]

2. Akova M. Dikkat Genişlemiş Spektrumlu Beta Laktamaz (GSBL) Var! ANKEM Dergisi 2004; 18(2): 98-103.
3. Stürenburg E, Mack D. Extended Spectrum Beta Lactamases Implications for The Clinical Microbiology Laboratory, Therapy and Infection Control. J Infect 2003; 47: 273-95. [CrossRef]

4. Giakkoupi P, Tzouvelekis SL, Tsakris A, Loukova V, Sofianou D, Tzelepi E. IBC-1 a Novel Integron Associated Class A Beta Lactamases with Extended Spectrum Properties Produced by an Enterobacter cloacae Clinical Strain. Antimicrob Agents Chemother 2000; 44(9): 2247-53. [CrossRef]

5. Vourli S, Tzouvelekis SL, Tzelepi E, Lebessi NJ, Miriagou V. Characterization of in In111 a Class 1 Integron That Carries the Extended-Spectrum Beta-Lactamase Gene bla IBC-1. FEMS Microbiol Lett 2003; 225: 149-53. [CrossRef]

6. Vourli S, Tzouvelekis SL, Tzelepi E. Characterization of Klebsiella pneumoniae Clinical Strain Producing a Rare Extended Spectrum Beta Lactamase (IBC-1). Int J Antimicrob Agents 2003; 21(5): 4957. [CrossRef]

7. Tzelepi E, Managa C, Platsouka E, Sofianou D, Paniara O, Legakis $\mathrm{NJ}$, et al. Extended Spectrum Beta Lactamase Types in Klebsiella pneumoniae and E. coli in Two Greek Hospitals. Int J Antimicrob Agents 2003; 21: 285-8.

8. Lebessi E, Stamos G, Foustoukou M, Vourli S, Legakis NJ, Tzouvelekis LS. Performance of Methods for Detection Of Extended- Spectrum Beta-Lactamases Applied to Clinical Enterobacterial Strains Producing IBC-Type of Beta-Lactamases. J Clin Microbiol 2003; 41(2): 912. [CrossRef]

9. Clinical and Laboratory Standards Institute. Performance Standards for Antimicrobial Susceptibility Testing. 22th ed. CLSI Supplement M100. Wayne, PA: CLSI, 2004.

10. Öksüz L, Gürler N. Escherichia coli ve Klebsiella spp. Suşlarında Genişlemiş Spektrumlu Beta Laktamazların Tiplendirilmesi ve Plazmid Profil Analizi. Mikrobiyoloji Bülteni 2009; 43: 183-94.

11. Bradford PA. Extended Spectrum Beta Lactamases in the 21st Century: Characterization, Epidemiology, and Detection of This Important Resistance Threat. Clin Microbiol Rev 2001; 14(4): 93351. [CrossRef]

12. Shaikh S, Fatima J, Shakil S, Rizvi SM, Kamal MA. Antibiotic resistance and extended spectrum beta-lactamases: Types, epidemiology and treatment. Saudi J Biol Sci 2015; 22(1): 90-101. [CrossRef]

13. Naas T, Poirel L, Nordmann P. Minor extended-spectrum beta-lactamases. Clin Microbiol Infect 2008; Suppl 1: 42-52.

14. Kartali G, Tzelepi E, Pournaras S, Kontopoulou C, Kontos F, Sofianou D, et al. Outbreak of Infections Caused by Enterobacter cloacae Producing the Integron-Associated Beta Lactamase IBC-1 in a Neonatal Intensive Care Unit of a Greek Hospital. Antimicrob Agents Chemother 2002; 46(5): 1577-80. [CrossRef]

15. Bonnin RA, Jousset AB, Emeraud C, Oueslati $S$, Dortet $L$, Naas $T$. Genetic Diversity, Biochemical Properties, and Detection Methods of Minor Carbapenemases in Enterobacterales. Front Med (Lausanne) 2021; 20(7): 616490. [CrossRef]

16. Cicek AC, Saral A, Iraz M, Ceylan A, Duzgun AO, Peleg AY, et al. OXAand GES-type-lactamases predominate in extensively drug-resistant Acinetobacter baumannii isolates from a Turkish University Hospital. Clin Microbiol Infect 2014; 20: 410-5. [CrossRef]

17. Naas T, Dortet L, lorga Bl. Structural and Functional Aspects of Class A Carbapenemases. Curr Drug Targets 2016; 17(9): 1006-28. [CrossRef]

18. Bektaş A, Güdücüoğlu H, Gürsoy NC, Berktaş M, Gültepe BS, Parlak $M$, et al. Genişlemiş Spektrumlu Beta-Laktamaz (GSBL) Üreten Escherichia coli ve Klebsiella pneumoniae Suşlarının GSBL Genlerinin Araştırılması. FLORA Dergisi 2018; 23(3): 116-23. [CrossRef] 
19. Copur Cicek A, Saral A, Ozad Duzgun A, Yasar E, Cizmeci Z, Ozlem Balci P,et al. Nationwide study of Escherichia coli producing extended-spectrum $\beta$-lactamases TEM, SHV and CTX-M in Turkey. J Antibiot (Tokyo) 2013; 66(11): 647-50. [CrossRef]

20. Dağlar D, Ongüt G, Oğünç D, Ozhak Baysan B, Demirbakan H, et al. Toplum kaynaklı üriner sistem enfeksiyonu etkeni Escherichia coli suşlarında GSBL enzim tiplerinin izoelektrik odaklama ve polimeraz zincir reaksiyonu yöntemleri ile araştırılması. Mikrobiyol Bul 2010; 44(3): 367-74.
21. Bush K. Past and Present Perspectives on $\beta$-Lactamases. Antimicrob Agents Chemother 2018; 2(10): e01076-18. 